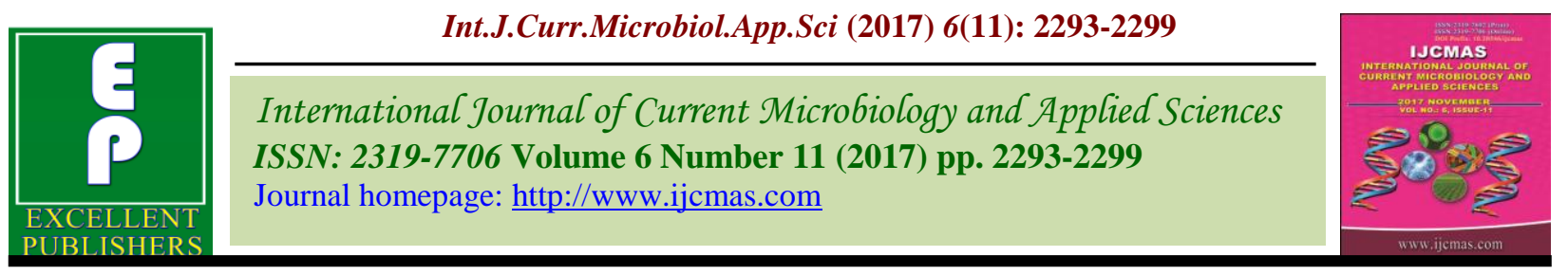

Original Research Article

https://doi.org/10.20546/ijcmas.2017.611.272

\title{
Prevalence of Uropathogens Causing Urinary Tract Infection and their Antimicrobial Susceptibility among the Reproductive Age Group in Theni District, India
}

\author{
S. Lallitha ${ }^{1 *}$, M. Lucy Nirmal Madona ${ }^{2}$, R. Sekhar1, S. Swarna ${ }^{1}$, \\ K.M. Mythreyee ${ }^{1}$ and Devisri ${ }^{1}$ \\ ${ }^{1}$ Department of Microbiology, Govt. Theni Medical College, Theni 625512, Tamilnadu, India \\ ${ }^{2}$ Department of Microbiology, Govt. Thoothukudi Medical College, Thoothukudi628008, \\ Tamilnadu, India \\ *Corresponding author
}

\section{A B S T R A C T}

Keywords

Urinary tract infection,

Uropathogens,

Antibiotic

susceptibility.

Article Info

Accepted:

17 September 2017

Available Online:

10 November 2017
Urinary Tract Infection (UTI) is one of the most common infections especially among the population in reproductive age group. This study was designed to isolate, characterize and to determine the antimicrobial susceptibility of uropathogens causing UTI, within the age group of 25-40 yrs attending Govt. Theni Medical College Hospital. The study identified Escherichia coli as the most common cause of UTI with $28 \%$ proportion among the positive cultures and most isolates of them were found susceptible to colistin (92.3\%), tigecycline (84.3\%), meropenam $(79.8 \%)$ and gentamicin $(79.4 \%)$.

\section{Introduction}

Urinary Tract Infection is the presence of symptoms like increased urinary frequency, urinary urgency and pain during urination which is the most common bacterial infection, accounts for about $25 \%$ of all infections.

UTI may occur in any population with any age group; however, the infection is most common in women of reproductive age group (Karki et al., 2004).

Although the Escherichia coli is being observed as a most common cause of UTI in all populations from different geographic regions its susceptibility pattern varied with reports (Gupta et al., 1999, Moges et al., 2002). It is important to note that the prevalence of antibiotic resistance among uropathogens is increasing worldwide (Bashir et al., 2008). The empirical selection of antibiotic should cover the likely pathogen with its likely susceptibility based on the recent records and local epidemiological information. Therefore, this study is aimed to determine the prevalence of uropathogens and their susceptibility pattern, which will help the clinician in choosing appropriate empirical therapy for UTI. 


\section{Materials and Methods}

All participants attending the Govt. Theni Medical College Hospital as either outpatient or inpatient with the symptoms of UTI within the age group of 25-40 were included in this study. The study conducted over the period of two years from January 2015 to August 2017 among the population of Theni district (Tamil Nadu, India).

\section{Sample collection}

The physician clinically examined all patients and those who suffer with the symptoms of UTI were empirically treated with the existing strategy $\left(3^{\text {rd }}\right.$ generation cephalosporin or fluoroquinolone) in our hospital.

Those who fail to respond to this empirical therapy were referred to the Microbiology Laboratory for Bacterial culture and susceptibility testing during their second visit. About $10-20 \mathrm{ml}$ of mid-stream urine sample was collected in a sterile urine container from the study participants and the sample was immediately transported to the laboratory at room temperature.

\section{Culture and identification of organism}

All samples were immediately processed after receipt at the Microbiology laboratory by inoculating $10 \mu \mathrm{L}$ of urine sample using calibrated inoculation loop on blood agar and MacConkey agar by following standard procedure. Then the culture plates were incubated at $35^{\circ} \mathrm{C}$ for overnight. After incubation, the culture plates were examined for the formation of significant number (> 30 $\mathrm{CFU}$ ) of Colony Forming Units (CFU). Then the samples found to have significant bacteriuria $\left(10^{5}\right.$ bacteria $\left./ \mathrm{mL}\right)$ were further processed towards the identification of organism by Standard Biochemical Tests (Razak and Gurushantappa, 2012) and
Antimicrobial Susceptibility Test by KirbyBauer disk diffusion method.

\section{Antimicrobial susceptibility testing}

Antimicrobial susceptibility testing was performed on Mueller-Hinton agar (HiMedia, Mumbai) by the Kirby-Bauer disk diffusion method according to Clinical and Laboratory Standards Institute (CLSI) guidelines [CLSI 2015] using E. coli ATCC 25922 and Staphylococcus aureus ATCC 25923 as quality control strains. Clinical isolates of $E$. coli or Klebsiella spp. were inoculated in saline and a direct colony suspension was prepared and adjusted to a 0.5 McFarland turbidity to contain $1.5 \times 10^{8} \mathrm{CFU} / \mathrm{mL}$. The test strain was lawn cultured on a MuellerHinton agar plate, then antibiotic disks were placed and the plate was incubated at $35^{\circ} \mathrm{C}$ for $16-18 \mathrm{~h}$ in ambient air. Following incubation, the diameter of the zone of inhibition was measured around each antibiotic disk and the data were stored in WHONET software v.5.6 (http://www.whonet.org). Cumulative antimicrobial susceptibility results were interpreted based on CLSI guidelines [CLSI, 2015]. Because of the non-availability of resistance criterion to colistin, a zone of inhibition of $<11 \mathrm{~mm}$ was recognized as nonsusceptible and was considered as resistant for this study. Furthermore, for tigecycline the US Food and Drug Administration (FDA) susceptibility criterion was used since CLSI breakpoints are not yet established.

\section{Data analysis}

The cumulative antimicrobial susceptibility testing data were retrieved from the computerized database (WHONET software ver. 5.6) and the prevalence of antimicrobial resistance was analyzed for Gram-positive and Gram-negative organisms using WHONET software. All analyzed data were presented as a percentage because of the 
variability in the number of tests conducted with different antibiotics.

\section{Results and Discussion}

A total of 2190 patient samples including 575 male and 1615 female were processed during the study period. Among them 133 and 528 were identified to have significant bacteriuria by culture identification. The leading causes of UTI were identified as Escherichia coli, Coagulase Negative Staphylococci, Klebsiella spp. and Pseudomonas aeruginosa (Table 1; Figure 1). Notably, leading causes of UTI were unchanged between male and female. Further, significant deviation was not observed among all causes of UTI. Interestingly, enterococci, citrobacter and enterobacter were higher among male when compared with female (Figure 1). Interestingly, Proteus spp. and Candida spp. was not observed among male participants in this study. The causative organisms were grouped as Gram-positive and Gram-negative and its susceptibility pattern was grossly analyzed. The study observed linezolid, vancomycin, and doxycycline, were having superior activity against Gram-positive organisms than other antimicrobials tested. Similarly, colistin, doripenam, tigecyclin, meropenam, pipercillin-tazobactam, and amikacin were active against Gram-negative organisms. Although the fluoroquinolones were the common choice for the treatment of UTI, this study observed less than 50\% efficacy against Gram-negative isolates. This could be owing to that the patients included in this study were empirically treated with the strategy in our hospital; those who fail to respond to this empirical therapy were investigated. Thus, this study observed high rate resistance not only to fluoroquinolones but also for all tested antimicrobials (Tables 2 and 3; Figs. 2 and 3 ).

Table.1 Organisms isolated from significant bacteriuria

\begin{tabular}{|l|l|l|l|l|}
\hline \multirow{2}{*}{ Organism } & \multicolumn{2}{|c|}{ Female } & \multicolumn{2}{c|}{ Male } \\
\cline { 2 - 5 } & No. & \multicolumn{1}{|c|}{ Percent } & No. & \multicolumn{1}{c|}{ Percent } \\
\hline Escherichia coli & 154 & $29.17 \%$ & 35 & $26.32 \%$ \\
\hline Staphylococcus, coagulase negative & 121 & $22.92 \%$ & 30 & $22.56 \%$ \\
\hline Non-fermenting gram negative rods & 67 & $12.69 \%$ & 16 & $12.03 \%$ \\
\hline Klebsiella spp. & 48 & $9.09 \%$ & 14 & $10.53 \%$ \\
\hline Edwardsiella sp. & 23 & $4.36 \%$ & 4 & $3.01 \%$ \\
\hline Morganella sp. & 22 & $4.17 \%$ & 8 & $6.02 \%$ \\
\hline Pseudomonas aeruginosa & 19 & $3.60 \%$ & 7 & $5.26 \%$ \\
\hline Enterococcus sp. & 18 & $3.41 \%$ & 8 & $6.02 \%$ \\
\hline Candida sp. & 15 & $2.84 \%$ & 0 & $0.00 \%$ \\
\hline Citrobacter spp. & 17 & $3.22 \%$ & 6 & $4.51 \%$ \\
\hline Staphylococcus aureus & 11 & $2.08 \%$ & 2 & $1.50 \%$ \\
\hline Enterobacter spp. & 4 & $0.76 \%$ & 3 & $2.26 \%$ \\
\hline Proteus spp. & 4 & $0.76 \%$ & 0 & $0.00 \%$ \\
\hline Others & 5 & $0.95 \%$ & 0 & $0.00 \%$ \\
\hline Total & $\mathbf{5 2 8}$ & $\mathbf{1 0 0}$ & $\mathbf{1 3 3}$ & $\mathbf{1 0 0}$ \\
\hline
\end{tabular}


Table.2 Antimicrobial susceptibility - Gram positive cocci (isolates from both male and female; $\mathrm{n}=190$ )

\begin{tabular}{|l|c|c|c|c|}
\hline Antibiotic name & Number & \%R & \%S & \%R 95\% C.I. \\
\hline Penicillin G & 148 & 91.2 & 8.1 & $86.0-95.6$ \\
\hline Ampicillin & 156 & 90.4 & 9 & $85.1-94.8$ \\
\hline Oxacillin & 143 & 60.1 & 22.4 & $51.6-68.1$ \\
\hline Cefazolin & 125 & 59.2 & 36 & $50.0-67.8$ \\
\hline Cefuroxime & 99 & 56.6 & 32.3 & $46.3-66.4$ \\
\hline Cefotaxime & 159 & 61 & 32.7 & $53.5-69.1$ \\
\hline Cefepime & 156 & 63.5 & 32.7 & $55.4-70.9$ \\
\hline Cefoxitin & 119 & 70.6 & 28.6 & $61.4-78.4$ \\
\hline Gentamicin & 143 & 26.6 & 67.1 & $19.7-34.8$ \\
\hline Ciprofloxacin & 169 & 65.1 & 18.3 & $57.3-72.2$ \\
\hline Levofloxacin & 169 & 52.7 & 20.7 & $44.9-60.4$ \\
\hline Norfloxacin & 41 & 75.6 & 17.1 & $59.3-87.1$ \\
\hline Trimethoprim/Sulfamethoxazole & 161 & 55.9 & 31.7 & $47.9-63.6$ \\
\hline Clindamycin & 169 & 25.4 & 65.1 & $19.2-32.8$ \\
\hline Erythromycin & 164 & 31.7 & 32.3 & $24.8-39.5$ \\
\hline Nitrofurantoin & 28 & 14.3 & 85.7 & $4.7-33.6$ \\
\hline Linezolid & 168 & 1.2 & 98.8 & $0.2-4.7$ \\
\hline Vancomycin & 161 & 1.2 & 97.5 & $0.8-6.5$ \\
\hline Doxycycline & 166 & 18.1 & 77.1 & $12.7-25.0$ \\
\hline Tetracycline & 134 & 24.6 & 68.7 & $17.8-32.9$ \\
\hline
\end{tabular}

Table.3 Antimicrobial susceptibility - Gram negative bacilli (isolates from both male and female; $n=455$ )

\begin{tabular}{|l|c|c|c|c|}
\hline Antibiotic name & Number & \%R & \%S & \%R 95\% C.I. \\
\hline Ampicillin & 396 & 94.4 & 3 & $91.5-96.4$ \\
\hline Piperacillin & 314 & 76.1 & 10.8 & $70.9-80.6$ \\
\hline Amoxicillin/Clavulanic acid & 398 & 84.4 & 10.8 & $80.4-87.7$ \\
\hline Piperacillin/Tazobactam & 416 & 18.8 & 67.1 & $15.2-23.0$ \\
\hline Cefazolin & 339 & 86.4 & 8.8 & $82.2-89.8$ \\
\hline Cefuroxime & 248 & 76.6 & 17.7 & $70.7-81.6$ \\
\hline Ceftazidime & 347 & 63.1 & 26.8 & $57.8-68.1$ \\
\hline Cefotaxime & 372 & 75.3 & 20.4 & $70.5-79.5$ \\
\hline Cefepime & 372 & 39.8 & 47.8 & $34.8-45.0$ \\
\hline Cefoxitin & 336 & 46.7 & 47.3 & $41.3-52.2$ \\
\hline Aztreonam & 389 & 60.7 & 26.5 & $55.6-65.6$ \\
\hline Doripenem & 234 & 17.9 & 76.9 & $13.3-23.6$ \\
\hline Ertapenem & 386 & 29.3 & 65.5 & $24.9-34.2$ \\
\hline Meropenem & 367 & 16.1 & 79.8 & $12.6-20.4$ \\
\hline Amikacin & 428 & 15.7 & 79.4 & $12.5-19.6$ \\
\hline Gentamicin & 361 & 50.1 & 45.2 & $44.8-55.4$ \\
\hline Nalidixic acid & 346 & 83.8 & 8.1 & $79.4-87.4$ \\
\hline Ciprofloxacin & 399 & 65.7 & 29.3 & $60.8-70.3$ \\
\hline Gemifloxacin & 328 & 58.8 & 31.7 & $53.2-64.1$ \\
\hline Levofloxacin & 398 & 58 & 31.4 & $53.0-62.9$ \\
\hline Norfloxacin & 293 & 66.6 & 30 & $60.8-71.9$ \\
\hline Ofloxacin & 373 & 61.1 & 31.9 & $55.9-66.0$ \\
\hline Trimethoprim/Sulfamethoxazole & 394 & 63.7 & 32.7 & $58.7-68.4$ \\
\hline Colistin & 416 & 7.7 & 92.3 & $5.4-10.8$ \\
\hline Nitrofurantoin & 290 & 36.2 & 56.2 & $30.7-42.1$ \\
\hline Doxycycline & 401 & 29.4 & 55.4 & $25.0-34.2$ \\
\hline Tetracycline & 345 & 49.9 & 44.3 & $44.5-55.3$ \\
\hline Tigecycline & 337 & 11.3 & 84.3 & $8.2-15.3$ \\
\hline
\end{tabular}


Fig.1 Significant bacteriuria: Organisms isolated - Female vs. Male

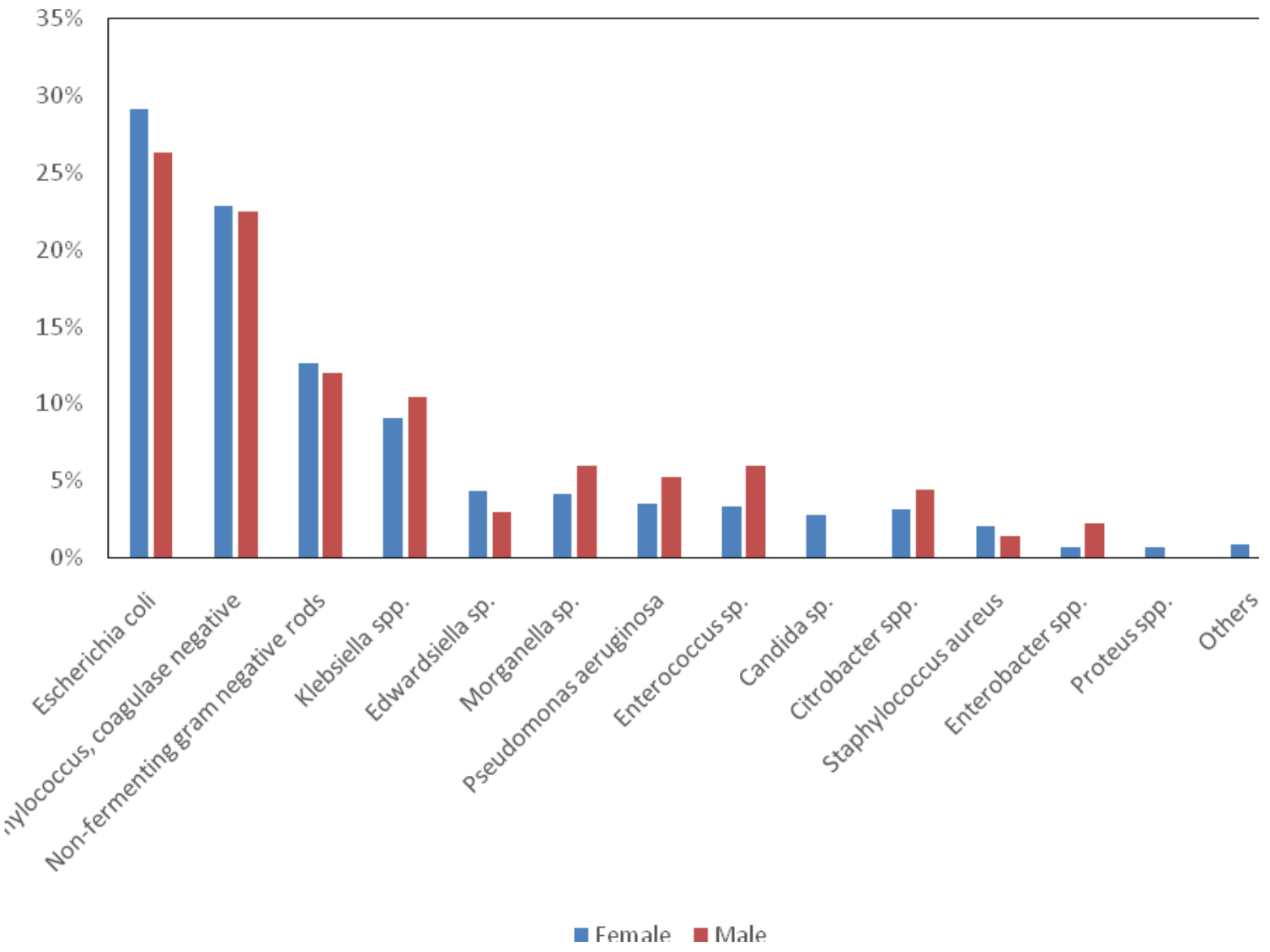

Fig.2 Susceptibility pattern of Gram positive cocci $(n=190)$

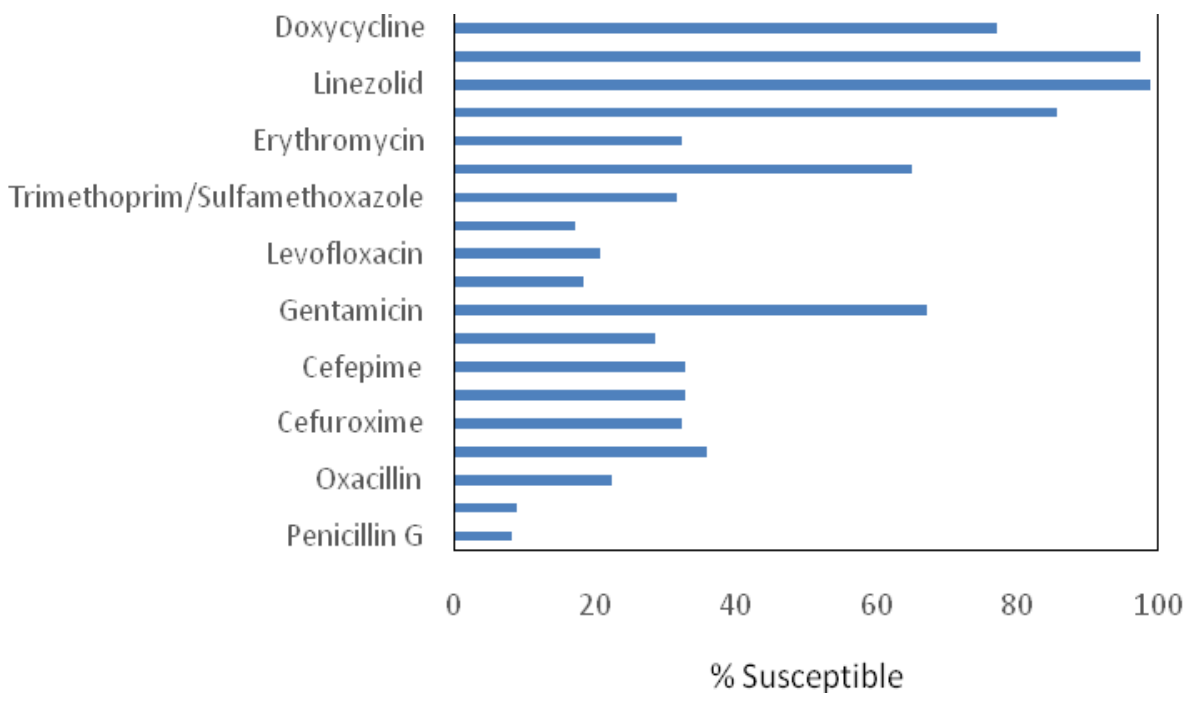


Fig.3 Susceptibility pattern of Gram negative bacilli $(n=455)$

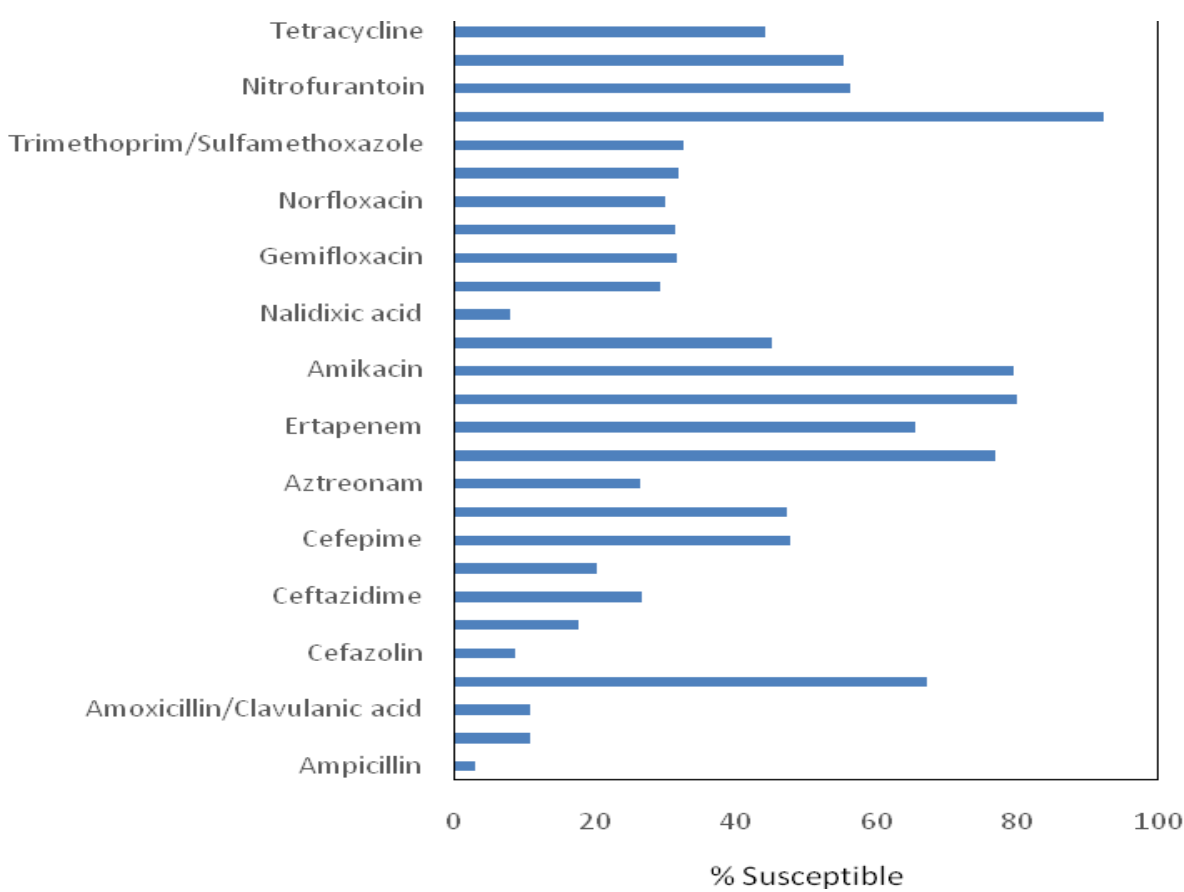

Our study results on the prevalence of pathogens were corroborated well with the earlier reports from India (Prakasam et al., 2012) as well as from abroad (Moges et al., 2002). The susceptibility data shows high prevalence of resistance when compared with other countries especially in Gram-negative organisms (Uwaezuoke et al., 2014). However, when compared with reports from India, the prevalence of resistance was similar to earlier reports (Sekar et al., 2016). This study shows that the predominant pathogen of UTI is Escherichia coli. This organism has acquired resistance to most of the commonly used antimicrobials may be due to indiscriminate usage of antibiotics. Periodic surveillance should be done to assess the prevalence of antimicrobial resistance as well as the emergence of newer types/mechanisms of resistance. These cumulative antimicrobial susceptibility data would help clinician to choose appropriate empirical antimicrobial form time to time.
The study observed E. coli and Coagulase Negative Staphylococci as the leading causes of UTI respectively among Gram-negative and Gram-positive organisms. The study observed nitrofurantoin or doxycycline could be used as empirical therapy for unresponsive cases with fluoroquinolones.

\section{Acknowledgement}

The authors are thankful to all staffs in the Department of Microbiology, Govt. Theni Medical College for their help in conducting this study and writing this manuscript.

\section{References}

Bashir, M.F., Qazi, J.I., Ahmad N Riaz, S. 2008. Diversity of urinary tract pathogens and drug resistant isolates of Escherichia coli in different age and gender groups of Pakistanis. Trop. J. Pharm. Res.7, 1025-103 
Collee, J.G., Miles, R.S., Watt, B. 2006. Tests for the identification of bacteria. In: Mackie and McCartney's Practical Medical Microbiology (Eds.)J.G. Collee, A.G. Fraser, B.P. Marmion, A. Simmons. $14^{\text {th }}$ ed. New York: Churchill Livingstone; 2006

Gupta KD, Scholes WE, Stamm. Increasing prevalence of antimicrobial resistance among uropathogens causing acute uncomplicated cystitis in women. Journal of the American Medical Association 1999; 281: 736-738

Karki, A., Tiwari, BR., Pradhan, S.B. 2004. Study of Bacteria Isolated from Urinary Tract Infections and Their Sensitivity Pattern. J. Nepal. Med. Assoc. 43, 200-2

Moges, A.F., Genetu, A., Mengistu, G. 2002. Antibiotic sensitivities of common bacterial pathogens in urinary tract infections at Gondar Hospital, Ethiopia. East Afr. Med. J. 79, 140-142.

Prakasam, A.K.C., Kumar, K.G.D., Vijayan, M. 2012. A Cross sectional study on distribution of urinary tract infection and their antibiotic utilization pattern in Kerala. Int. J. Pharm. Tech. Res. 4, 1309- 1316.

Prakash, D and R. S. Saxena, "Distribution and antimicrobial susceptibility pattern of bacterial pathogens causing urinary tract infection in Urban Community of Meerut City, India," ISRN Microbiology, vol. 2013

Razak, S, S.K., Gurushantappa, V. 2012. Bacteriology of urinary tract infection and antibiotic susceptibility pattern in a tertiary care hospital in South India. Int. J. Med. Sci. Public Health. 1, 109-112.

Sekar, R., Mythreyee, M., Srivani, S., Amudhan, M. 2016. Prevalence of antimicrobial resistance in Escherichia coli and Klebsiella spp. in rural South India. J. Glob. Antimicrob. Resist. 5, 80-85

Tambekar D.H, D. V. Dhanorkar, S. R. Gulhane, V. K. Khandelwal, and M. N. Dudhane, "Antibacterial susceptibility of some urinary tract pathogens to commonly used antibiotics," African Journal of Biotechnology, vol. 5, no. 17, pp. 1562-1565, 2006.

Uwaezuoke J. C., and J. N. Ogbulie, "Antibiotic sensitivity pattern of urinary tract pathogens in Port-Harcourt, Nigeria," Journal of Applied Sciences and Environmental Management, vol. 10, no. 3, pp. 103-107, 2006

\section{How to cite this article:}

Lallitha, S., M. Lucy Nirmal Madona, R. Sekhar, S. Swarna, K.M. Mythreyee and Devisri. 2017. Prevalence of Uropathogens Causing Urinary Tract Infection and their Antimicrobial Susceptibility among the Reproductive Age Group in Theni District. Int.J.Curr.Microbiol.App.Sci. 6(11): 2293-2299. doi: https://doi.org/10.20546/ijcmas.2017.611.272 